\title{
Epidemiology and location of rugby injuries treated in US emergency departments from 2004 to 2013
}

\author{
Vani Sabesan' \\ Zachary Steffes ${ }^{2}$ \\ Daniel J Lombardo' \\ Graysen R Petersen-Fitts' \\ Toufic R Jildeh ${ }^{2}$ \\ 'Department of Orthopaedic Surgery, \\ ${ }^{2}$ Wayne State University School of \\ Medicine, Detroit, MI, USA
}

This article was published in the following Dove Press journal:

Open Access Journal of Sports Medicine

26 October 2016

Number of times this article has been viewed
Abstract: Rugby participation in the US is increasing, and with its inclusion in the 2016 Summer Olympics, the increased participation rates are expected to continue. Naturally, as participation increases, so too do rugby-related injuries. The difference in injury patterns with regard to age and gender illustrates differences in how the game is being played. Understanding what accounts for these emerging injury patterns will help guide future injury prevention efforts. This study provides an update on injury rates for the growing population of rugby players in the US, especially young players. Our results focus on the variation of injury types and the injury rates of various levels of rugby players, including youth, collegiate, and recreational. Using injury data from the National Electronic Injury Surveillance System, we analyzed data in rugby patients for age, gender, body region, type of injury, and severity. We employed statistical weights to calculate national injury estimates. During the 10 years studied, the trend in the number of rugby injuries among all age groups showed a statistically significant increase $(R=0.804, P=0.005)$. The average age of injury was $21.5 \pm 6.3$ years with facial and head injuries constituting $>33 \%$ of all injuries, representing a proportional increase of $>10 \%$. Men were most frequently injured in the face (18.2\%) and head (15.9\%); women were most frequently injured in the head $(23 \%)$ and shoulder (12.3\%). There were 9,059 concussions, constituting $7 \%$ of all injuries.

Keywords: rugby, injury pattern, epidemiology

\section{Introduction}

Rugby is a full-contact team sport and the direct forerunner of American football. The relative rapid growth in population and participation of the sport has been attributed to rugby's acquisition of professional status in Europe in $1995 .{ }^{1}$ In 2014, the International Rugby Board, rugby's global governing body, released a statement indicating that an estimated 6.6 million people in 119 countries play rugby, an astounding increase of 2 million more participants worldwide from just 4 years before. While rugby is not considered a traditional American sport, the International Rugby Board reported $>1.4$ million participants in the US in $2013,{ }^{2}$ a major increase from the 81,678 registered US participants just 5 years prior. ${ }^{3}$ In addition, it was estimated that $>2$ million American youth participants in 2012 took part in the Rookie Rugby program. ${ }^{4}$

A lack of required protective equipment in rugby differentiates it from other full-contact sports, such as American football, men's ice hockey, and men's lacrosse. While these other sports mandate the use of protective headgear and other equipment to prevent injuries, mouth guards are the only protective gear required in rugby. ${ }^{5}$ One study found that a lack of regulatory mandates for protective equipment in rugby could
Department of Orthopaedic Surgery, Wayne State University School of Medicine, 10000 Telegraph Road, Taylor, MI 48I20, USA

Tel + I 3134297218

Fax + I 3133757225

Email sabes00I@gmail.com 
be responsible for a tripled injury rate compared to American college football. ${ }^{6}$ While rugby injuries have been studied in many countries where the sport is traditionally popular, ${ }^{1,6-23}$ a few studies have focused on the injury rates in the US. ${ }^{24-31}$ Extensive research has been done internationally to understand the prevalence of rugby-specific injuries, ${ }^{8,9,12,14,16,20-22}$ variations of injury rates across competition levels, $, 2,10,11,13$ the effects of protective equipment on injury prevention, $1,6,18,19,23$ and comparisons of rugby injuries to injuries occurring in other sports. ${ }^{7,17}$ Broadly, these studies suggest that senior rugby league players are more likely to injure their head and neck and sustain muscular injuries compared to junior players, who are more likely to injure their knees and sustain a fracture.

With the surge in popularity of rugby in the US, particularly among younger players, it is important to understand the risks and common injuries associated with this sport. There is only one documented example, a study published in 2006, which reports rugby-related injuries in the US from 1978 to 2004. ${ }^{31}$ The report reveals that rugby injury patterns tended to differ by both age and gender. Specifically, women were more likely to suffer from contusions/abrasions and injuries to the knee. Men were more likely to suffer from strain/ sprains, lacerations, and fractures, and the most commonly injured area was the face. In addition, athletes older than 18 years typically suffered from strain/sprains, lacerations, fractures, and contusions/abrasions, while athletes younger than 18 years were more likely to present with concussions. ${ }^{31}$ To our knowledge, this was the first and the only report that looked at rugby injury data in the US on a nationwide level.

This study provides an update on injury rates for the growing population of rugby players in the US, especially young players. Our results focus on the variation of injury types and the injury rates of various levels of rugby players, including youth, collegiate, and recreational.

\section{Materials and methods}

Ethical approval was not required by the Wayne State University Institutional Review Board because the information is from a publicly available database and the information is de-identified. The data for rugby injuries were collected using the National Electronic Injury Surveillance System (NEISS), which is a representative sample of hospitals in the US and territories under the direction of the Consumer Product Safety Commission (CPSC). This collection of NEISS hospitals is a stratified probability sample of hospitals with trained coders that review all emergency department (ED) records daily and enter demographic, treatment, and injury data into the NEISS. During this process, each case is assigned a CPSC-specific product code that helps designate what activity or products were involved in the injury. With the use of a multiplier based on the size of the hospital and the number of hospitals similarly sized throughout the US, national estimates can then be calculated by summing the weighting values of all cases that present to each participating ED. ${ }^{32}$

With the use of the rugby product code (3234), we evaluated all patients presenting to US EDs in the NEISS database with rugby injuries from January 1, 2004, through December 31,2013 , the most recent 10 -year period with the available data. The use of the code allowed us to gather information that included all injuries obtained while playing rugby and injuries involving rugby equipment and spectators at rugby events. All cases in which the narrative description stated that the injury did not occur while actively participating in rugby were excluded. The sampling error using the NEISS data was calculated using the following formula: no of injuries \pm $(1.96 \times$ no of injuries $\times$ generalized coefficient of variation $){ }^{32}$

Demographic information on the injured participants included race, gender, and age. Information specific to each injury sustained included body part, diagnosis, disposition, and a description of cause of injury. We analyzed these data with a focus on age, gender, body region, type of injury, and severity based on codes specific to the database. Participants were divided into groups based on age, 7-17 years old, 18-23 years old, and more than 23 years old, which were broken down based on isolating the college-aged rugby players (the demographic that is expected to consist of the largest number of participants). The body region and type of injury were derived from the CPSC diagnosis and categorizations. The disposition of each case was recorded as either treated or released, treated or transferred, admitted, observation, or left against medical advice. These outcomes were used as a measure of severity of each injury.

The incidence rates of rugby injuries were calculated using rugby participation rates from the Outdoor Foundation's participation reports of 2013. The Outdoor Foundation is a not-for-profit organization focused on encouraging and enhancing the experiences of people in the outdoors. Annually, the organization conducts a series of online interviews and surveys to assess participation in various outdoor sports. Similar to the NEISS database, a weighting technique is used to accurately reflect the participation rates for the entire US population. For this study, we used available rugby participation figures from 2007 to 2013 for all Americans older than 6 years. ${ }^{33}$ We used the Hazard Screening Report for Team Sports of 2004 to compare the relative rate of injury between other sports and rugby. ${ }^{34}$ SPSS software (Version 21.0; IBM Corporation, Armonk, NY, USA) was used for data analysis. Linear regression analysis was performed to evaluate change 
in the number of rugby injuries per year. The incidence rates were calculated using annual numbers of injuries from the NEISS database and participation numbers from the Outdoor Foundation. Injury proportion ratios (IPRs) were used to assess comparisons of male and female demographics, comparisons of age groups, and comparisons of injury severities. The IPRs were calculated as the rate of each specific injury out of all injuries occurring among men compared to woman. For example, the IPR for fractures was calculated as follows:

$\mathrm{IPR}=\frac{\text { no of male fractures } / \text { total no of injuries in men }}{\text { no of female fractures } / \text { total no of injuries in women }}$

\section{Results}

\section{Patterns of rugby injuries}

Over 10 years, the national estimate of individuals presented to US EDs with rugby injuries was 128,813 . The sampling error using NEISS data was calculated using an estimated generalized coefficient of variation of 0.08 or $8 \%$ of the estimated sample size. For a $95 \%$ confidence interval, the sampling error was $128,813 \pm 20,198(108,615-149,011)$. There was an average incidence rate of 17.19 injuries per 1,000 participants for a 7-year period. The demographic information is summarized in Table 1 . The majority of reported injuries occurred among males (78.4\%), among players $18-23$ years old (59.4\%), and among Caucasians (54\%). The most common reported sites of injury were the head (17.4\%), face (15.7\%), shoulder (14.7\%), and ankle (10\%; Figure 1).

The most common types of injuries were sprains/ strains $(26.1 \%)$, fracture $(17.8 \%)$, lacerations $(15.5 \%)$,

Table I Demographics

\begin{tabular}{lll}
\hline & & National estimate \\
\hline Gender & & \\
Male & $78.4 \%$ & 100,989 \\
Female & $21.6 \%$ & 27,824 \\
Average age & $21.5 \pm 6.3$ years & \\
Age group & & \\
7-I7 years & $19.1 \%$ & 24,603 \\
I8-23 years & $59.4 \%$ & 76,515 \\
>23 years & $21.6 \%$ & 27,695 \\
Race & & \\
White & $54 \%$ & 69,575 \\
Not stated & $37.5 \%$ & 48,272 \\
Black & $3.9 \%$ & 5,047 \\
Other & $3.4 \%$ & 4,335 \\
Asian & $1.0 \%$ & 1,249 \\
American Indian/ & $0.1 \%$ & 92 \\
Alaskan native & & \\
Native Hawaiian/ & $0.2 \%$ & 243 \\
Pacific Islander & & \\
\hline
\end{tabular}

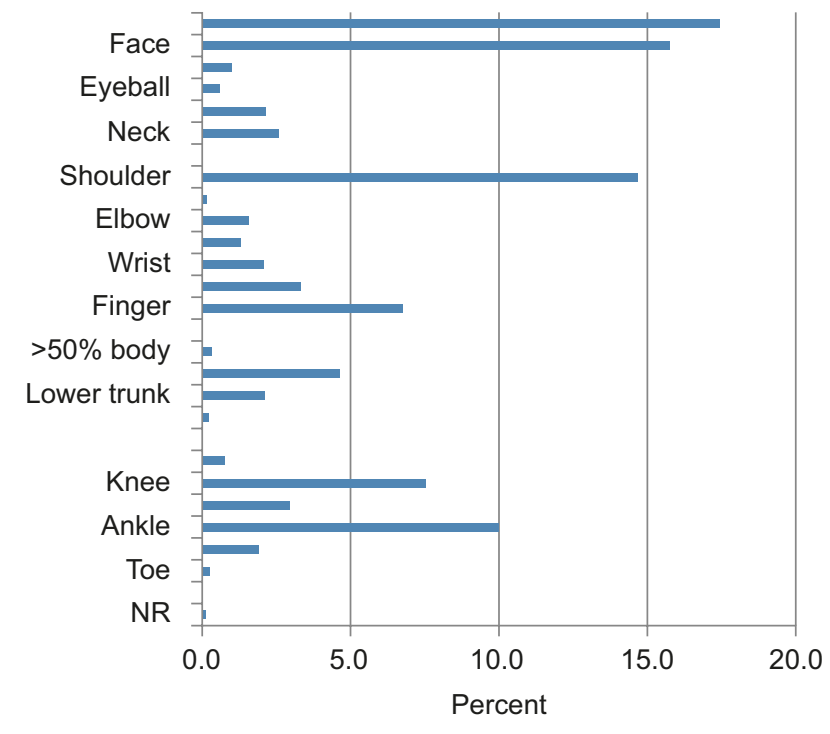

Figure I Percentage of injuries separated by location.

Abbreviation: NR, not reported.

and contusions (14.4\%; Figure 2). The body region most commonly affected varied for each type of injury (Table 2). Contusions most commonly occurred in the upper trunk, dislocations most commonly occurred in the shoulder, and strains/sprains occurred with the highest rate at the ankle. Concussions (40\%), lacerations (15.3\%), and contusions $(6.7 \%)$ were the most commonly occurring injuries in the head region (Table 3 ).

Over the course of the 10-year period studied, the number of rugby players with injuries fluctuated from 10,300/year to $15,300 /$ year. The overall trend in the number of rugby injuries among all age groups showed a statistically significant increase $(R=0.804, P=0.005)$. No trend was found regarding the annual incidence rate between 2007 and 2013, but we observed two peaks, one in 2008 and one in 2011 (Figure 3).

We found that the relative risk for sustaining an injury in basketball, football, and baseball, when compared to rugby, was $1.19,1.22$, and 0.64 , respectively $(P<0.0001)$.

\section{Injuries by age}

Each age group suffered injuries at different locations in varying proportions (Figure 2). Among the 7-to-17-year-old demographic, the most common areas of injury were in the head (20.2\%), shoulder (14.2\%), and ankle (12\%), which was similar to the 18-to-23-year-old demographic with the most common areas of injuries occurring in the head (18.5\%), face (17.7\%), shoulder (15\%), and ankle (10.5\%; Figure 2). In the over-23year-old group, the most common area of injury was in the face $(17.6 \%)$, shoulder (14.1\%), finger (8.1\%), and upper trunk (7.2\%; Figure 2). Variations for distribution rate between age 


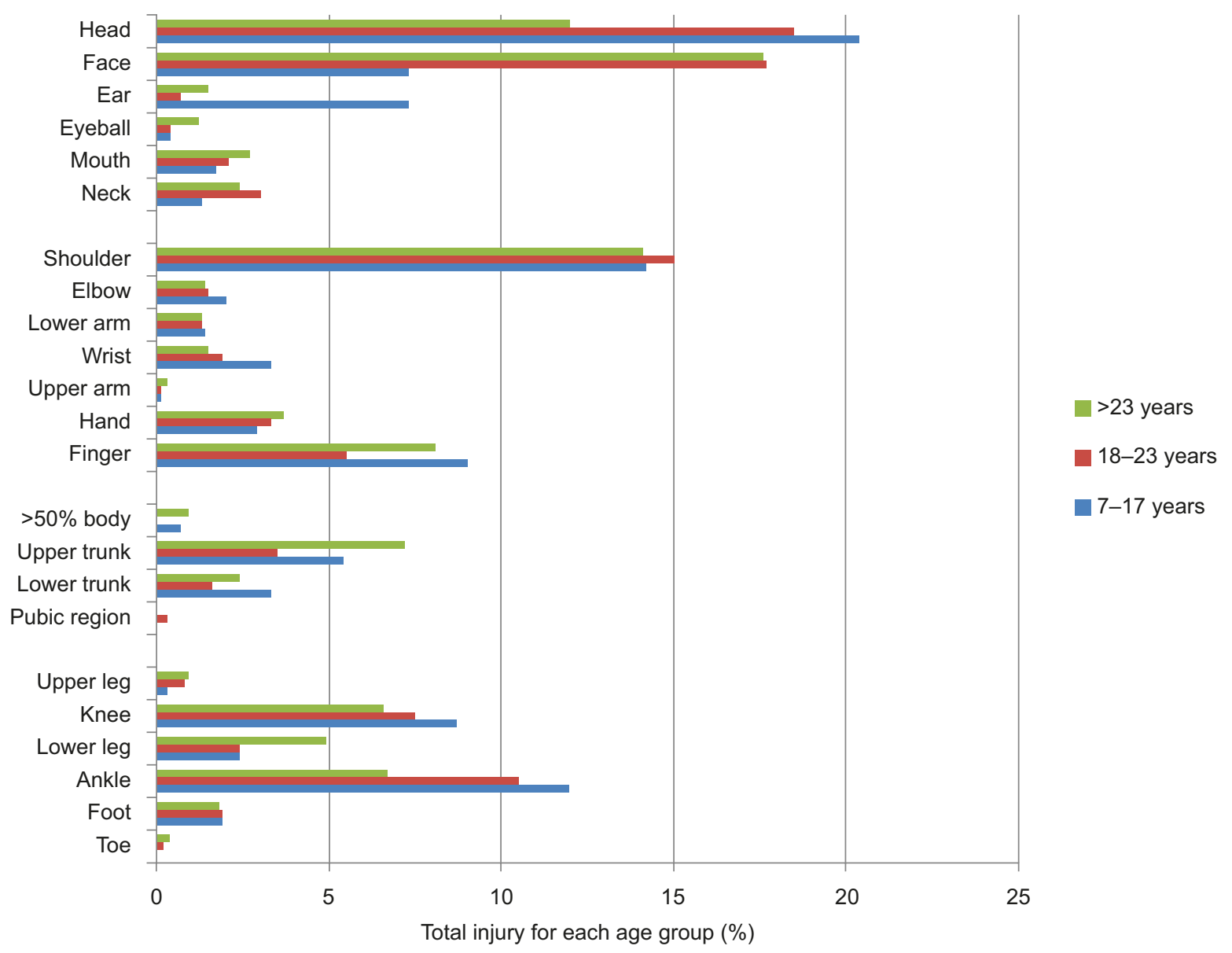

Figure $2 \mathrm{~A}$ chart illustrating the anatomic region of injury as a function of age.

Note: Ages were grouped into 7-17 years, 18-23 years, and $>23$ years.

Table 2 Proportion of locations at which each injury type occurred

\begin{tabular}{lllllll}
\hline Body part & Contusion/abrasion (\%) & Dislocation (\%) & Fracture (\%) & Hematoma (\%) & Laceration (\%) & Sprain/strain (\%) \\
\hline Head & 6.70 & 0.00 & 0.10 & 4.00 & 15.30 & 0.00 \\
Face & 13.60 & 0.00 & $\mathbf{2 2 . 4 0}$ & 5.50 & $\mathbf{6 1 . 4 0}$ & 0.00 \\
Ear & 0.40 & 0.00 & 0.00 & $\mathbf{4 2 . 9 0}$ & 4.60 & 0.00 \\
Eyeball & 3.40 & 0.00 & 0.00 & 3.70 & 0.10 & 0.00 \\
Mouth & 0.00 & 0.00 & 0.00 & 0.00 & 13.10 & 0.00 \\
Neck & 1.00 & 0.00 & 0.30 & 0.00 & 0.00 & 8.20 \\
Shoulder & 9.00 & $\mathbf{6 1 . 8 0}$ & 16.80 & 0.00 & 0.00 & $\mathbf{2 3 . 3 0}$ \\
Upper arm & 0.10 & 0.00 & 0.70 & 0.00 & 0.00 & 0.00 \\
Elbow & 3.60 & 4.40 & 1.60 & 0.00 & 0.80 & 1.20 \\
Lower arm & 1.60 & 0.00 & 5.00 & 0.00 & 040 & 0.40 \\
Wrist & 2.20 & 0.00 & 4.20 & 0.00 & 0.10 & 3.30 \\
Hand & 8.90 & 0.90 & 7.50 & 0.00 & 0.50 & 1.20 \\
Finger & 5.40 & $\mathbf{2 2 . 0 0}$ & 13.60 & 0.00 & 1.30 & 6.40 \\
>50\% body & 0.30 & 0.00 & 0.00 & 0.00 & 0.00 & 0.00 \\
Upper trunk & 19.50 & 0.80 & 2.00 & 0.00 & 0.00 & 2.40 \\
Lower trunk & 4.40 & 1.70 & 0.80 & 0.00 & 0.00 & 2.80 \\
Pubic region & 0.40 & 0.00 & 0.00 & 17.40 & 0.00 & 0.00 \\
Upper leg & 2.50 & 0.00 & 0.40 & 0.00 & 0.10 & 0.90 \\
Knee & 6.10 & 6.60 & 1.30 & 0.00 & 0.70 & 19.00 \\
Lower leg & 6.50 & 0.00 & 7.80 & 26.60 & 0.80 & 0.90
\end{tabular}

Note: The percentages are summed up by column. Bold values show the highest values in each set. 
Table 3 Proportion of head-related injuries to include concussion that only occurs in this region of the body

\begin{tabular}{llllllll}
\hline & Concussion (\%) & Contusion/abrasion (\%) & Dislocation (\%) & Fracture (\%) & Hematoma (\%) & Laceration (\%) & Sprain/strain (\%) \\
\hline Head & $\mathbf{4 0}$ & 6.70 & 0.00 & 0.10 & 4.00 & 15.30 & 0.00 \\
\hline
\end{tabular}

Note: Bold values show the highest values in each set.

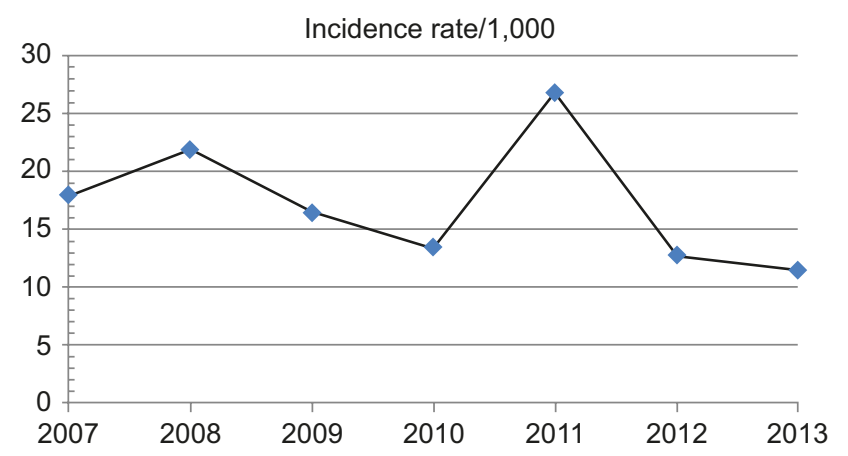

Figure 3 A chart illustrating the rugby injury incidence rate per 1,000 players between the years 2007 and 2013.

groups were shown in the regions of the upper leg (IPR 3.19), lower trunk (IPR 2.8), hand (IPR 2.75), and toe (IPR 1.91).

The most common type of injuries among the 7-to-17-yearold demographic was sprain/strains $(31.5 \%)$, contusions (16.8\%), and fractures (16.6\%). Among the 18-to-23-year-old demographic, sprain/strain $(25.8 \%)$, fracture $(16.6 \%)$, and lacerations $(16.4 \%)$ were the most common injuries. In players older than 23 years, the most common injuries were sprain/ strain $(22.4 \%)$, fractures $(22.3 \%)$, and lacerations (19.8\%).

\section{Injuries by gender}

The majority of rugby injuries occurred in males for all age groups, with men accounting for $79.9 \%$ of the injuries in the 7-to-17-year-old, $74.4 \%$ of the injuries in the 18-to-23-yearold, and $88.4 \%$ of the injuries in the 23 and older age groups. Men were most frequently injured in the face (18.2\%), head (15.9\%), and shoulder (15.3\%; Figure 4). Women were most frequently injured in the head $(23 \%)$, shoulder $(12.3 \%)$, and knee $(11.5 \%)$. The biggest variation for injury proportion rates between men and women was shown in the regions of the mouth (IPR 4.23), ear (IPR 3.48), face (IPR 2.62), and eyeball (IPR 2.57).

Men were most prone to sprain/strains (23.9\%), fractures (18.6\%), and lacerations (18.6\%). Women were also most prone to sprain/strains $(34.4 \%)$, followed by contusions (15.7\%) and fractures (15.1\%). Lacerations (IPR 3.24), dislocations (IPR 1.66), and hematomas (IPR 1.31) were much more frequent in men than women.

\section{Injury severity}

Almost all the injuries were managed acutely in the ED, with $97.3 \%$ being treated in the ED and released. Only $1.1 \%$ of players were admitted to the hospital. The college age group required hospital admission less frequently $(0.7 \%$; IPR 0.6$)$ compared to the 7-to-17-year-old group (1.2\%; IPR 1.1) and over 23-year-old group (2.2\%; IPR 1). Injuries in males were also more severe compared to females, with $1.4 \%$ versus $0.4 \%$ of females requiring hospital admission. Internal organ injuries were often the most severe of these injuries with $4.0 \%$ requiring hospital admission. Concussion management occurred in $2.4 \%$, requiring observation status in the hospital.

\section{Discussion}

Previous studies have shown that rugby participation in the US has grown steadily since the earliest participation records of $1978 .{ }^{31}$ As the sport grows, it is gaining popularity from different demographic groups and the media. As mentioned previously, the Outdoor Foundation's research participation report showed a doubling in rugby participation from 2006 to 2010. With growing participation numbers, rugby-related injury patterns continue to change. The growing number of rugby participants necessitates improved awareness of the types and patterns of injuries incurred while playing this full-contact sport and focused prevention programs.

This study aimed to characterize the pattern of injury among today's rugby players. We hypothesized that there would be an increase in the overall number of rugby-related injuries due to the increased participation rates. The number of reported rugby injuries did increase by up to 9,300 per year; however, the pattern of injuries remained consistent with previous investigations. ${ }^{31}$ In our study, the average age of injury decreased by 1.5 years among men (average age 21.8 years) and 1.1 years among women (average age 20.1 years) compared to previously reported statistics. ${ }^{31}$ The rates of face and head injuries as a proportion of total body injuries increased by $10 \%$ when compared to the previous decade.

When compared to other sports, basketball and football players have a higher relative risk of injury (1.19 and 1.22, respectively) when compared to those who play rugby. Conversely, baseball players have a lower relative risk of injury (0.64) when compared to rugby players.

Our results demonstrated a higher prevalence of rugby injuries among males, with approximately twice the rate of injuries in the face and four times the rate of lacerations compared to females. Understanding what accounts for the 


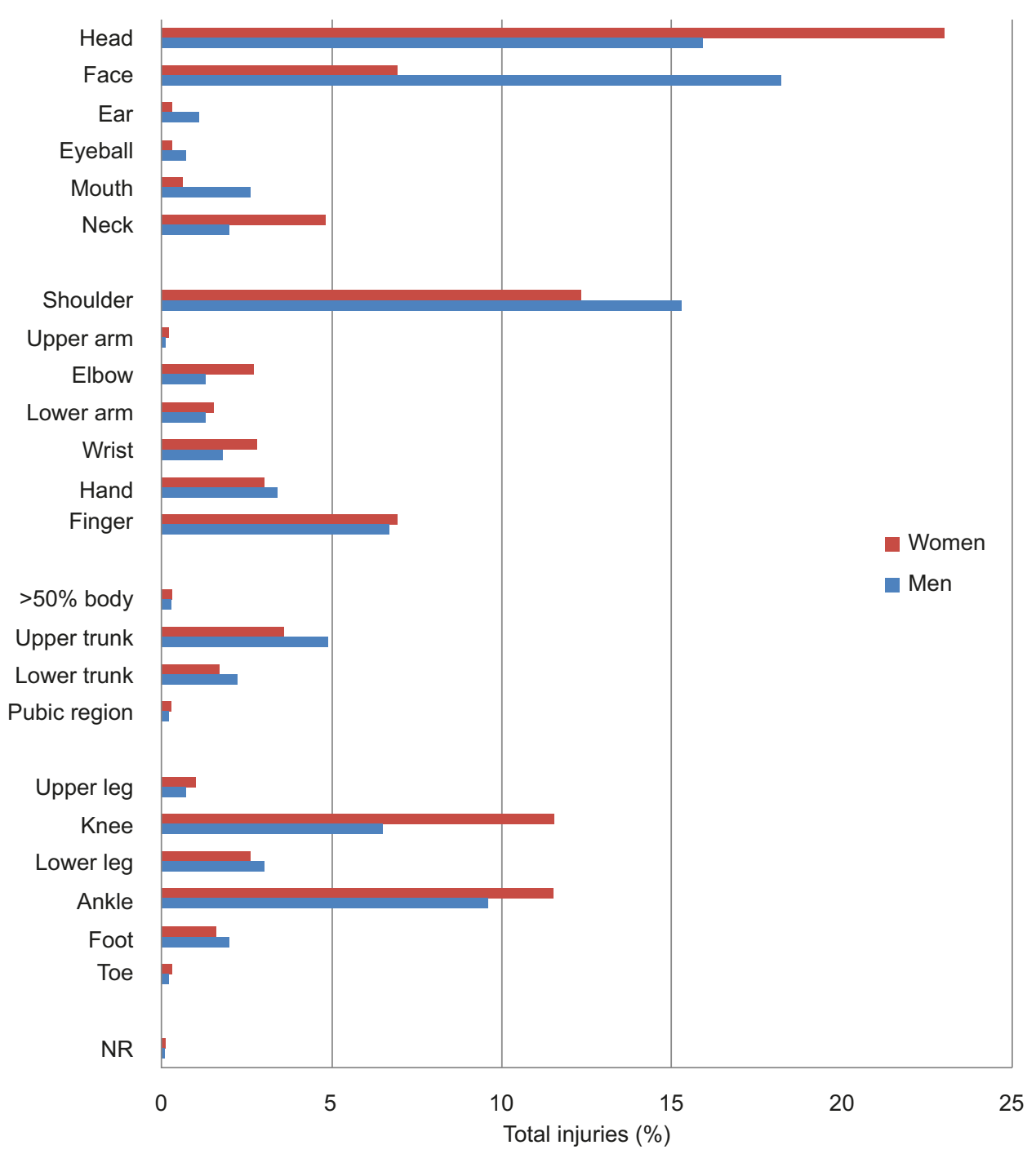

Figure $4 \mathrm{~A}$ chart illustrating the anatomic region of injury as a function of gender.

Note: Men and women genders were investigated.

Abbreviation: NR, not reported.

higher rates of injuries among male rugby players could provide a targeted intervention to assist in the prevention of these injuries. One previously proposed theory for this difference includes a higher frequency of foul play in the men's game. Another theory takes into account that men playing rugby are more likely to have a background in playing American football. ${ }^{31}$ A 2011 study issued by USA rugby found a cross-participation rate of $37.8 \%$ between rugby and tackle football among all US rugby players. ${ }^{35}$ If boys in the US grow up learning to tackle with helmets and facemasks, habits could translate to a tackling form in rugby that makes them more susceptible to injury. Yard and Comstock et al also pointed out a geographic difference in the higher proportion of head and facial injuries sustained among male rugby players. Our study demonstrates that head and face injuries continue to be the most common injury types among US rugby players.
What is concerning is our results demonstrated a doubling in the number of concussions since Yard and Comstock $^{31}$ last studied rugby injuries. A systematic review of rugby injuries in adolescents found that recurrent concussions have been reported, some with as little as 3 weeks seperation. ${ }^{36}$ These findings raise concerns over the lack of consistent protective headgear used among rugby players. While the rules of rugby mandate the use of a mouth guard, other protective equipment is limited and optional. All players are allowed the option of wearing a soft, padded helmet during play. While previous studies have found evidence supporting the use of padded headgear for the prevention of lacerations and abrasions, ${ }^{6,15,17,19,23,26,37-39}$ our findings strongly support mandating the use of protective headgear to reduce the incidence of these concussion injuries. Future work should focus on reducing the incidence of head and face injuries among rugby players. 
Injuries among college-aged (19-24 years old) participants are significant. The age group represents the fastestgrowing demographic of rugby participants, incurring the highest number of injuries. Despite this, regardless of age, there were similar patterns of types of injuries and body areas seen from our results. This offers a potential area for future research on protective equipment regulation among all age groups of rugby participants. Since rugby is not governed by the NCAA, the formation of a regional or national governing body could be beneficial in providing participation and safety regulations, as well as a more standardized education of coaching and officiating. Education of players, coaches, and referees has been previously studied as a strategy for rugby injury prevention in other countries and has shown some promise in reducing injury rates. ${ }^{14,38,40}$

Limitations of this study are related to the inherent issues seen in large databases that are dependent on the quality and categorization of the data. In addition, the NEISS database does not include rugby injuries treated outside the ED (ie, outpatient medical clinics, minor injuries assessed and treated by athletic trainers, and injuries not receiving any medical attention). Severe injuries leading to death or catastrophic injury without transport to the ED were also not included in this study. Despite this, there were no such injuries reported to the report of National Center for Catastrophic Sports Injury Research on catastrophic injuries occurring from 1982 to 2012.41

With the inclusion of rugby in the Summer Olympics beginning in $2016,{ }^{42}$ the boom in rugby participation can only be expected to continue. With increased rugby participation, we suggest continued surveillance, improved standardization, and regulation of safety equipment to prevent rugby-related injuries. Greater surveillance and reporting of patterns of injury and severity can enable clinicians to be the drivers of reform for better safety in this sport. In addition, our results raise concerns with the increased rates of severe injuries such as concussions or facial injuries, emphasizing a need for further research into the effectiveness and potential implementation of rules that mandate more extensive use of protective equipment.

Rugby is indeed growing in worldwide popularity and will likely continue to do so. With growing popularity, there has been an increased rate of injuries for rugby players in the US. Our study provides important information on injury patterns and trends for rugby in the US so that effective prevention strategies may be developed for safe participation.

\section{Disclosure}

Vani Sabesan discloses the following conflicts of interest. She has worked as a paid consultant in Arthrex, Inc., has received research support from Exactech, Inc. and Tornier, and was a board or committee member of Michigan Orthopaedic Society. The other authors report no conflicts of interest in this work.

\section{References}

1. Garraway WM, Lee AJ, Hutton SJ, Russell EB, Macleod DA. Impact of professionalism on injuries in rugby union. Br J Sports Med. 2000; 34(5):348-351.

2. International Rugby Board. International Rugby Board Year in Review 2013. 2013. Dublin, Ireland.

3. International Rugby Board. International Rugby Board Year in Review 2009. 2009. Dublin, Ireland.

4. International Rugby Board. International Rugby Board Year in Review 2012. 2012. Dublin, Ireland.

5. Quarrie KL, Gianotti SM, Chalmers DJ, Hopkins WG. An evaluation of mouthguard requirements and dental injuries in New Zealand rugby union. Br J Sports Med. 2005;39(9):650-651.

6. Marshall SW, Waller AE, Dick RW, Pugh CB, Loomis DP, Chalmers DJ. An ecologic study of protective equipment and injury in two contact sports. Int J Epidemiol. 2002;31(3):587-592.

7. Delahunty SE, Delahunt E, Condon B, Toomey D, Blake C. Prevalence of and attitudes about concussion in Irish schools' rugby union players. J Sch Health. 2015;85(1):17-26.

8. Edgar M. Tackling rugby injuries. Lancet. 1995;345(8963):1452-1453.

9. Freitag A, Kirkwood G, Scharer S, Ofori-Asenso R, Pollock AM. Systematic review of rugby injuries in children and adolescents under 21 years. Br J Sports Med. 2015;49(8):511-519.

10. Gabbett TJ. Incidence of injury in junior and senior rugby league players. Sports Med. 2004;34(12):849-859.

11. Gabbett TJ, Ullah S, Finch CF. Identifying risk factors for contact injury in professional rugby league players - application of a frailty model for recurrent injury. J Sci Med Sport. 2012;15(6):496-504.

12. Gabbett TJ, Ullah S, Jenkins D, Abernethy B. Skill qualities as risk factors for contact injury in professional rugby league players. J Sports Sci. 2012;30(13):1421-1427.

13. Gardner AJ, Iverson GL, Williams WH, Baker S, Stanwell P. A systematic review and meta-analysis of concussion in rugby union. Sports Med. 2014;44(12):1717-1731.

14. Gianotti SM, Quarrie KL, Hume PA. Evaluation of RugbySmart: a rugby union community injury prevention programme. J Sci Med Sport. 2009; 12(3):371-375.

15. Hollis SJ, Stevenson MR, McIntosh AS, Shores EA, Collins MW, Taylor CB. Incidence, risk, and protective factors of mild traumatic brain injury in a cohort of Australian nonprofessional male rugby players. Am J Sports Med. 2009;37(12):2328-2333.

16. Junge A, Cheung K, Edwards T, Dvorak J. Injuries in youth amateur soccer and rugby players - comparison of incidence and characteristics. Br J Sports Med. 2004;38(2):168-172.

17. Marshall SW, Loomis DP, Waller AE, et al. Evaluation of protective equipment for prevention of injuries in rugby union. Int J Epidemiol. 2005; 34(1):113-118.

18. McIntosh AS, McCrory P. Effectiveness of headgear in a pilot study of under 15 rugby union football. Br J Sports Med. 2001;35(3):167-169.

19. McIntosh AS, McCrory P, Finch CF, Best JP, Chalmers DJ, Wolfe R. Does padded headgear prevent head injury in rugby union football? Med Sci Sports Exerc. 2009;41(2):306-313.

20. Palmer-Green DS, Stokes KA, Fuller CW, England M, Kemp SP, Trewartha G. Training activities and injuries in English youth academy and schools rugby union. Am J Sports Med. 2015;43(2):475-481.

21. Patricios JS. Rugby contact and collisions - clinical challenges of a global game. Curr Sports Med Rep. 2014;13(5):326-333.

22. Patricios JS, Kemp S. Chronic traumatic encephalopathy: rugby's call for clarity, data and leadership in the concussion debate. Br J Sports Med. 2014;48(2):76-79. 
23. Wilson BD. Protective headgear in rugby union. Sports Med. 1998; 25(5):333-337.

24. Collins CL, Micheli LJ, Yard EE, Comstock RD. Injuries sustained by high school rugby players in the United States, 2005-2006. Arch Pediatr Adolesc Med. 2008;162(1):49-54.

25. Dietzen CJ, Topping BR. Rugby football. Phys Med Rehabil Clin NAm. 1999;10(1):159-175.

26. Kahanov L, Dusa MJ, Wilkinson S, Roberts J. Self-reported headgear use and concussions among collegiate men's rugby union players. Res Sports Med. 2005;13(2):77-89.

27. Kaplan KM, Goodwillie A, Strauss EJ, Rosen JE. Rugby injuries: a review of concepts and current literature. Bull NYU Hosp Jt Dis. 2008; 66(2):86-93.

28. Kerr HA, Curtis C, Micheli LJ, et al. Collegiate rugby union injury patterns in New England: a prospective cohort study. Br J Sports Med. 2008; 42(7):595-603.

29. Micheli LJ, Riseborough ED. The incidence of injuries in rugby football. J Sports Med. 1974;2(2):93-98.

30. Peck KY, Johnston DA, Owens BD, Cameron KL. The incidence of injury among male and female intercollegiate rugby players. Sports Health. 2013;5(4):327-333.

31. Yard EE, Comstock RD. Injuries sustained by rugby players presenting to United States emergency departments, 1978 through 2004. J Athl Train. 2006;41(3):325-331.

32. U.S. Consumer Product Safety Commission. NEISS: National Electronic Injury Surveillance System A Tool for Researchers. Washington, DC: U.S. Consumer Product Safety Commission; 2000.
33. The Outdoor Foundation. Outdoor Participation Report. Outdoor Foundation; 2013.

34. Mills A, Rutherford G, Marcy A. Hazard Screening Report Team Sports. Consumer Product Safety Commission; 2004. Bethesda, MD, USA.

35. SGMA [webpage on the Internet]. Single Sport Report - Rugby; 2011. Available from: http://usarugby.org/documentation/about/sgmasurvey-2011.pdf. Accessed January 15, 2015. Jupiter, FL, USA.

36. Bleakley C, Tully M, O'Connor S. Epidemiology of adolescent rugby injuries: a systematic review. J Athl Train. 2011;46(5):555-565.

37. Jones SJ, Lyons RA, Evans R, et al. Effectiveness of rugby headgear in preventing soft tissue injuries to the head: a case-control and video cohort study. Br J Sports Med. 2004;38(2):159-162.

38. Benson BW, McIntosh AS, Maddocks D, Herring SA, Raftery M, Dvorak J. What are the most effective risk-reduction strategies in sport concussion? Br J Sports Med. 2013;47(5):321-326.

39. Kemp SP, Hudson Z, Brooks JH, Fuller CW. The epidemiology of head injuries in English professional rugby union. Clin J Sport Med. 2008; 18(3):227-234

40. Brown JC, Verhagen E, Knol D, Van Mechelen W, Lambert MI. The effectiveness of the nationwide BokSmart rugby injury prevention program on catastrophic injury rates. Scand J Med Sci Sports. 2016;26(2): 221-225.

41. Mueller FO, Kucera KL, Cox LH, Cantu RC. Catastrophic Sports Injury Research - Thirty First Annual Report. 2013. Chapel Hill, NC, USA.

42. Associated Press. Golf, Rugby Added for 2016 and 2020; 2009. Available from: http://www.espn.com/olympics/news/story?id=4545111. Accessed February 19, 2015.
Open Access Journal of Sports Medicine

\section{Publish your work in this journal}

The Open Access Journal of Sports Medicine is an international, peer-reviewed, open access journal publishing original research, reports, reviews and commentaries on all areas of sports medicine. The journal is included on PubMed. The manuscript management system is completely online and includes a very quick and fair
Dovepress

peer-review system. Visit http://www.dovepress.com/testimonials.php to read real quotes from published authors. 